\title{
Temperature and airflow setting in dual-duct ventilation systems
}

\author{
Edward Przydrozny ${ }^{1}$, and Aleksandra Przydrozna ${ }^{2, *}$ \\ ${ }^{1}$ Wrocław University of Science and Technology, Department of Air Conditioning, Heating, Gas \\ Engineering and Air Protection, ul. Norwida 4/6, 50-373 Wrocław, Poland \\ ${ }^{2}$ Max Fordham, 42-43 Gloucester Cres, Camden Town, London, NW1 7PE, United Kingdom
}

\begin{abstract}
Past experiences of excess energy consumption and malfunctioning controls introduced prejudice when considering dual-duct ventilation systems during design stages. Modern technologies, however, can be used to improve performance and control of dual-duct systems, thus making these a sensible and safe design option. In the paper, we discuss challenges associated with setting the warm and cold supply air temperatures and how these set-points affect the airflows. We present limitations in temperature settings, due to instantaneous room thermal conditions and the individual design temperature requirements. Portions of warm and cold air (the ratio of these in the ventilating airflow) affect the transport costs of ventilating airflow. In many cases, rational control of warm and cold air temperature set-points, in a yearly cycle, enables distribution of similar portions of warm and cold air within the system. Even airflows in warm and cold air installations minimise the overall flow resistance, so that the air transport costs are minimal. Simultaneously, apart from minimising the energy for air transport, the primary energy demand for air treatment should be controlled and minimised.
\end{abstract}

\section{Introduction}

Dual-duct ventilation systems are designed to provide simultaneous thermal comfort in many rooms with different instantaneous heat gains [8]. In these systems, warm and cold airflows are first thermally-treated centrally, then distributed within the building, to be finally supplied to each room [11-13]. Prior to air supply into a room, warm airflow is mixed with cold airflow in mixing boxes, in portions that ensure the required instantaneous temperature set-points. Portions of warm and cold air distributed to mixing boxes can vary and be the subject of ongoing adjustments during the use of individual rooms. These individual adjustments may be triggered by changes in either external or internal conditions [7]. Dual-duct systems can be relatively energy-intensive due to simultaneous thermal treatment of two airflows with significantly varying temperature set-points [9]. Modern technologies aimed at energy conservation in HVAC and system's operation control can be

\footnotetext{
*Corresponding author: aleksandraprzydrozna@gmail.com
} 
successfully applied to improve dual-duct systems' performance [6-9]. A standard approach to conserving energy demand in dual-duct HVAC involves modifying systems by adding either air recirculation or heat recovery [1-17]. Przydróżny \& Przydróżna propose a new approach, to energy-efficiency in dual-duct systems, which combines advantages of both heat recovery and air recirculation [7]. In this paper, we focus on the control aspects of dual-duct ventilation system operation in the context of adjusting temperature set-points.

\section{Method}

We propose modelling to simulate annual operation of dual-duct systems under investigation. The approach to modelling and equations used to derive results are now outlined. The use of dual-duct ventilation systems enables individual adjustments of the air temperature set-points in rooms with different and independently varying heat gains. Even if a central single-stage air treatment is considered, airflow can be supplied to each room at different temperatures to meet individual design set-points. This can be achieved without any additional thermal treatment, only by varying portions of warm and cold air in the mixing boxes. Ventilating airflows for individual rooms are calculated on the base of:

$$
V_{i}=Q_{\text {shmax }}^{i} /\left(\Delta t_{r}^{\max } \rho c_{p}\right)
$$

wherein: $V_{i}$ - ventilating airflow (volumetric) serving an $i$-th room $\left(\mathrm{m}^{3} / \mathrm{s}\right), Q_{\text {shmax }}^{i}$ maximum heat gains in the $i$-th room $(\mathrm{kW}), \Delta t_{r}{ }^{\max }$ - maximum supply air temperature increment in the $i$-th room $(\mathrm{K}), \rho$ - supply air density $\left(\mathrm{kg} / \mathrm{m}^{3}\right), c_{p}$ - specific heat of supply air $(\mathrm{kJ} /(\mathrm{kg} \mathrm{K}))$. The supply airflow to individual rooms is the sum (mixture) of warm and cold air:

$$
V_{i}=V_{i}^{c}+V_{i}^{w}
$$

wherein: $V_{i}^{c}$ - cold airflow supplied to the $i$-th room $\left(\mathrm{m}^{3} / \mathrm{s}\right), V_{i}^{w}-$ warm airflow supplied to the $i$-th room $\left(\mathrm{m}^{3} / \mathrm{s}\right)$. The relationships of cold airflow $(c)$ and warm airflow $(w)$ in the ventilating airflow are described as:

$$
c_{i}=V_{i}^{c} / V_{i} \quad w_{i}=V_{i}^{w} / V_{i}
$$

wherein: $c_{i}$ - cold airflow in the ventilating airflow for $i$-th room, $w_{i}$ - warm airflow in the ventilating air for the $i$-th room. In systems with constant airflows, the flow rate of air treated and transported to mixing boxes is the sum of the airflows supplied to all ventilated rooms:

$$
V=\sum V_{i} \quad V^{c}=\sum V_{i}^{c} \quad V^{w}=\sum V_{i}^{w} c=V^{c} / V \quad w=V^{w} / V
$$

To reduce the energy demand for air treatment, the extract air recirculation or heat recovery from the exhaust air is used. The central air treatment processes are influenced by both the external conditions (e.g. instantaneous external air parameters, insolation, location of the building and rooms) and internal conditions (e.g. design air temperature, air change rate).

\section{Supply air temperature adjustments}

Fig.1. presents a schematic of the duct distribution route for supply (warm and cold) and extract airflows in a dual-duct ventilation system. The system in Fig. 1 supplies air to n-rooms (zones) with individually adjustable air temperature set-points. The individual 
supply airflows are derived from eq. (1). In terms of the entire system, assuming constant airflows, the overall thermally-treated airflow equals the sum of the airflows supplied to all rooms, see eq. (4). Instantaneous supply air temperatures for individual rooms are expressed as:

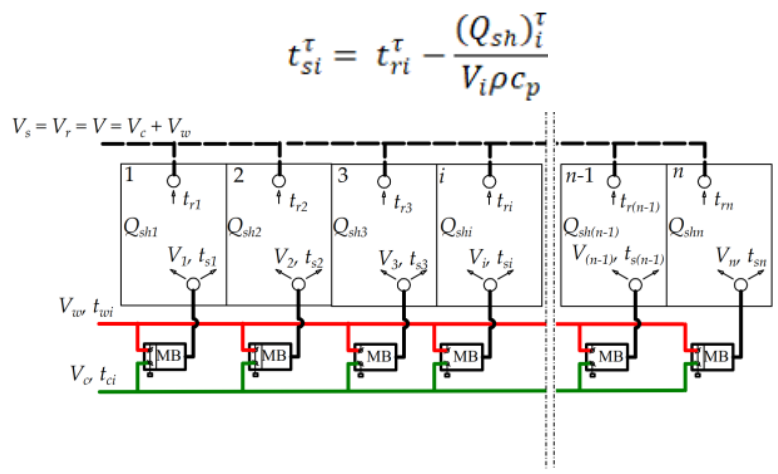

Fig. 1. Duct distribution route for supply (warm and cold) and extract airflows in a dual-duct ventilation system.

wherein: $t_{s i}^{\tau}$ - instantaneous temperature of the supply air to the $i$-th room $\left({ }^{\circ} \mathrm{C}\right), t_{r i}^{\tau}-$ instantaneous air temperature in the $i$-th room $\left({ }^{\circ} \mathrm{C}\right),\left(Q_{s h}\right){ }_{i}$ - temporary sensible heat gain in the $i$-th room $(\mathrm{kW})$. The instantaneous supply air temperatures required for individual zones depend on: the design room air temperature set-points, instantaneous thermal conditions and individual supply airflow rates to each room. The individual supply airflows are mixtures of warm and cold air, and their temperatures can be determined from:

$$
t_{s i}^{\tau}=c_{i}^{\tau} \cdot t_{c i}^{\tau}+w_{i}^{\tau} \cdot t_{w i}^{\tau}
$$

Coefficients $c_{i}^{\tau}$ and $w_{i}^{\tau}$ are the instantaneous portions of cold and warm air in the ventilating airflow supplied into the $i$-th room. Portions of warm and cold air are in the range: $\left.c_{i}^{\tau} \in<1 ; 0\right)$ and $\left.w_{i}^{\tau} \in<0 ; 1\right)$. In other words, if $c_{i}^{\tau}=1$ and $w_{i}^{\tau}=0$, only cold airflow is supplied, whereas if $c_{i}^{\tau}=0$ and $w_{i}^{\tau}=1$, only warm airflow is supplied. Based on the above, we can determine the minimum temperature of the warm air and the maximum temperature of the cold air at which the dual-duct system can deliver the design temperature set-points in the rooms under instantaneous thermal conditions. The instantaneous minimum temperature of the warm air, thus equals the supply air temperature for $c_{i}^{\tau}=0$ and $w_{i}^{\tau}=1$, and:

$$
t_{w i}^{\tau}=t_{s i}^{\tau}=t_{w \min }^{\tau}=\left(t_{r i}^{\tau}-\frac{\left(Q_{s h}\right)_{i}^{\tau}}{V_{i} \rho c_{p}}\right)_{\max }^{\tau}
$$

for $i \in\{1,2, \ldots, \mathrm{n}\}$. In contrast, the instantaneous maximum cold air temperature equals the supply air temperature for $c_{i}^{\tau}=1$ and $w_{i}^{\tau}=0$, and:

$$
t_{c j}^{\tau}=t_{s j}^{\tau}=t_{c \max }^{\tau}=\left(t_{r j}^{\tau}-\frac{\left(Q_{s h}\right)_{j}^{\tau}}{V_{j} \rho c_{p}}\right)_{\min }^{\tau}
$$


for $j \in\{1,2, \ldots, \mathrm{n}\}$. The warm and cold air temperatures, derived from eq. (7) and (8), determine the critical conditions for these temperatures, but these are insufficient conditions in the context of the entire dual-duct system. Globally, for the entire dual-duct system, the instantaneous supply air temperature (weighted average) can be determined from:

$$
t_{s i}^{\tau}=c \cdot t_{c}^{\tau}+w \cdot t_{w}^{\tau}=\left(t_{r}^{a v}\right)^{\tau}-\frac{\sum_{i=1}^{n}\left(Q_{s h}\right)_{i}^{\tau}}{V_{i} \rho c_{p}}
$$

The average instantaneous temperature of the extract air $\left(t_{r}^{a v}\right)^{\tau}$ depends on the flow rates and temperatures of the extract air expelled from individual rooms and can be expressed as:

$$
\left(t_{r}^{a v}\right)^{\tau}=\frac{\sum_{i=1}^{n}\left(V_{i} t_{r i}\right)^{\tau}}{V}
$$

As a result, we conclude that dual-duct systems provide the design air temperatures in all serviced rooms, provided that the following conditions are met:

$$
\begin{aligned}
t_{c}^{\tau} \leq t_{c j}^{\tau}=\left(t_{r j}-\frac{\left(Q_{s h}\right)_{j}}{V_{j} \rho c_{p}}\right)_{\min }^{\tau} & t_{w}^{\tau} \geq t_{w i}^{\tau}=\left(t_{r i}-\frac{\left(Q_{s h}\right)_{i}}{V_{i} \rho c_{p}}\right)_{\min }^{\tau} \\
\left(t_{r}^{a v}\right)^{\tau}=\frac{\sum_{i=1}^{n}\left(V_{i} t_{r i}\right)^{\tau}}{V}-\frac{\sum_{i=1}^{n}\left(Q_{s h}\right)_{i}^{\tau}}{V \rho c_{p}} & \left(t_{s}^{a v}\right)^{\tau}=c \cdot t_{c}^{\tau}+w \cdot t_{w}^{\tau}
\end{aligned}
$$

The expressions in (11) define the set of conditions to ensure that the dual-duct system provides design temperature set-points in all serviced rooms. These conditions have no operational limitations related to: the minimum cold air temperature, the maximum warm air temperature, the range of portions of warm and cold air in the supply air. These conditions can be ensured under significant number of combinations of temperatures and portions of cold and warm air.

\section{Portions of warm and cold air in ventilating airflow}

In dual-duct ventilation systems, the supply air temperature set-points for individual rooms can vary at any time and be adjusted by mixing two airflows (warm and cold) in mixing boxes. The air of similar thermodynamic properties is delivered to all mixing boxes at a given time, whereas the airflows upon leaving the boxes can have widely varying temperatures. Thus, in individual mixing boxes, the portions of incoming warm and cold air tend to vary depending on the temperature of the cold and warm airflows. The temperature of warm and cold air has also a direct influence on their portions at the inlet to distribution routes for mixing boxes. For instance $[8,11,14]$ discuss setting the temperature of warm and cold air as a function of the external air temperature. These works, however, do not outline any rules and procedures for assuming the temperature of warm and cold air in the annual cycle of the dual-duct ventilation systems' operation. Thermal conditions required for the correct operation of the dual-duct ventilation systems are outlined in expressions (11). Portions of warm and cold air in the ventilating airflow come as a result of the adopted warm and cold air temperature set-points. To illustrate the principle, we consider rooms ventilated by dual-duct system and we present the required portions of warm and cold air, for different global warm and cold temperature set-points, to ensure the design air temperature in individual rooms. We perform both global and local dynamic simulations of warm and cold airflows in the annual operation cycle to understand the overall implications 
of adjusting system's set-points. In our simulations we assume constant airflows, which are estimated on the base of the maximum heat gains of individual rooms, with a maximum supply air temperature increase of $7 \mathrm{~K}$. We assume similar design set-points in all the ventilated rooms, i.e. the design room air temperature of $20^{\circ} \mathrm{C}$ in the winter and a follow-up temperature in summer when the external air temperature exceeds $20^{\circ} \mathrm{C}$. Fig. 2 shows, as a function of external temperature, heat balances in four ventilated rooms under consideration (Fig. 2a) and a total thermal balance for all the rooms (Fig. 2b). For the assumed thermal balances in Fig. 2.(a-b), Fig. 2.(c) shows, as a function of the external air temperature, the supply air temperature increments in individual rooms and the average temperature increase for the entire system. For the assumed room air temperature and the supply air temperature increments in Fig. 2c., Fig. 3. shows the suggested supply air temperatures, as a function of the external air temperature.
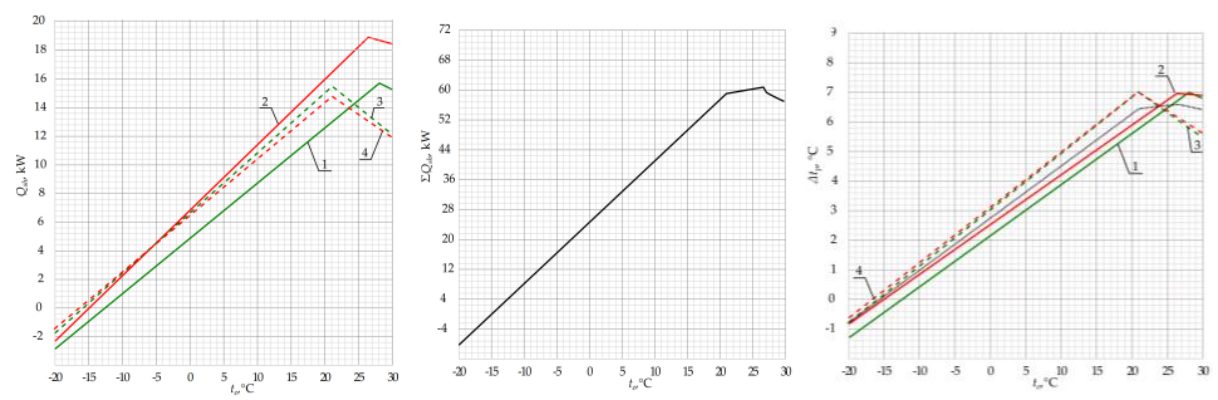

Fig. 2. (a-b) Heat balances: (a) local (for individual rooms 1-4) and (b) global (for the entire system) as a function of the external air temperature. Fig. 2. (c) Supply air temperature increments: local (individual rooms) and global (average for the entire system) as a function of the external air temperature.

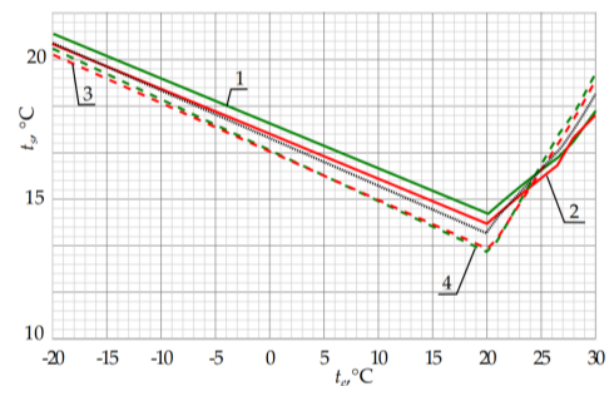

Fig. 3. Suggested supply air temperatures as a function of external air temperature.

These supply air temperatures are achieved by mixing thermally-treated warm and cold airflows. Fig. 4. shows, as a function of external air temperature, examples of recommended warm and cold air temperatures.

Fig. 5. (a-b) show characteristic temperatures as a function of external air temperature $\left(t-t_{e}\right.$ graph), for the total heat load in all rooms, i.e. warm $\left(t_{w}\right)$ and cold $\left(t_{c}\right)$ air temperatures, room air temperature $\left(t_{r}\right)$ and average supply air temperature $\left(t_{s}\right)$. Portions of warm $(w)$ and cold $(c)$ air, ensuring the average supply air temperature required by the ventilation system, are also shown as a function of external air temperature. 

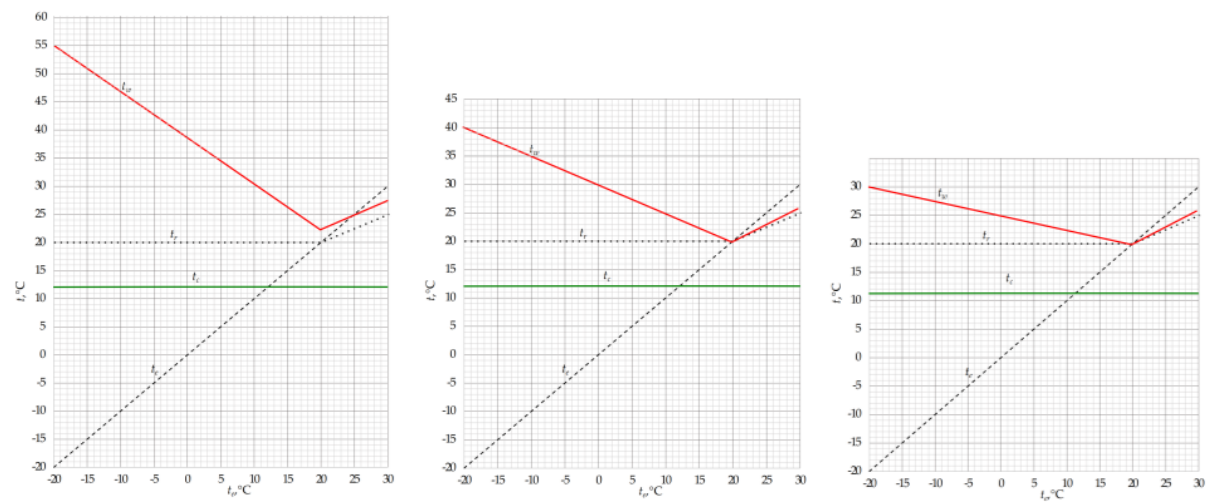

Fig. 4. Warm and cold air temperatures recommended for dual-duct systems.
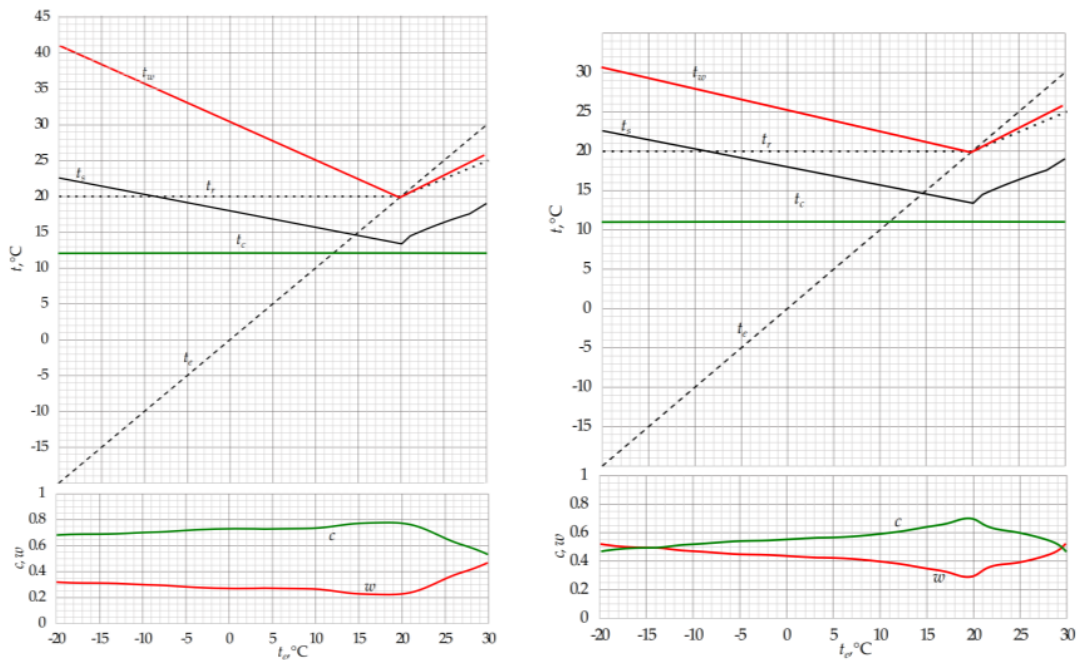

Fig. 5.Temperatures of warm and cold air, average supply air temperature and portions of warm $(w)$ and cold $(c)$ airflows assumed at the inlet to distribution installations: (a) adopted according to [14]; (b) adopted according to [8].

Fig. 6. shows the $t$ - $t_{e}$ graph with warm and cold air temperatures as a function of external air temperature, where constant and equal portions of warm and cold airflows are maintained. Fig. 7. shows portions of warm and cold airflows distributed into the mixing boxes for supply air to individual rooms for warm and cold airflow temperatures presented in Figure 8. By comparing the graphs of warm and cold airflows in Fig. 6. and Fig. 7., we conclude that with equal warm and cold airflows distributed within the dual-duct ventilation system, the required conditions in all rooms can be achieved by varying portions of warm and cold airflows distributed into individual mixing boxes. 


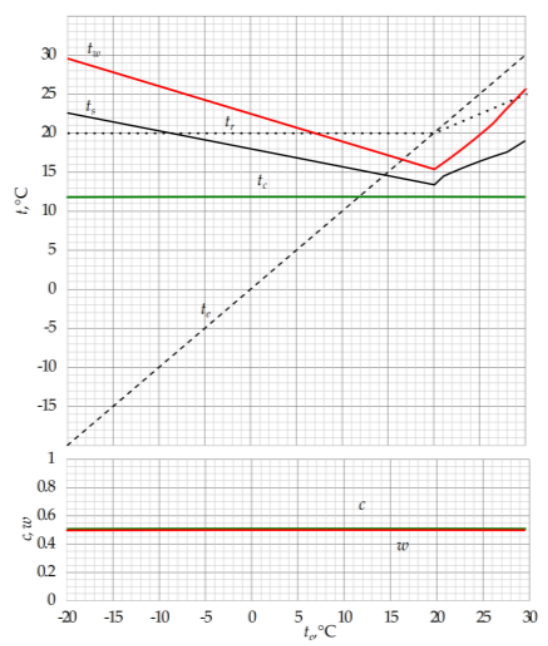

Fig. 6. Temperatures of warm and cold air, average supply air temperature for a case with equal portions of warm $(w)$ and cold $(c)$ airflows at the inlet to distribution ducts.
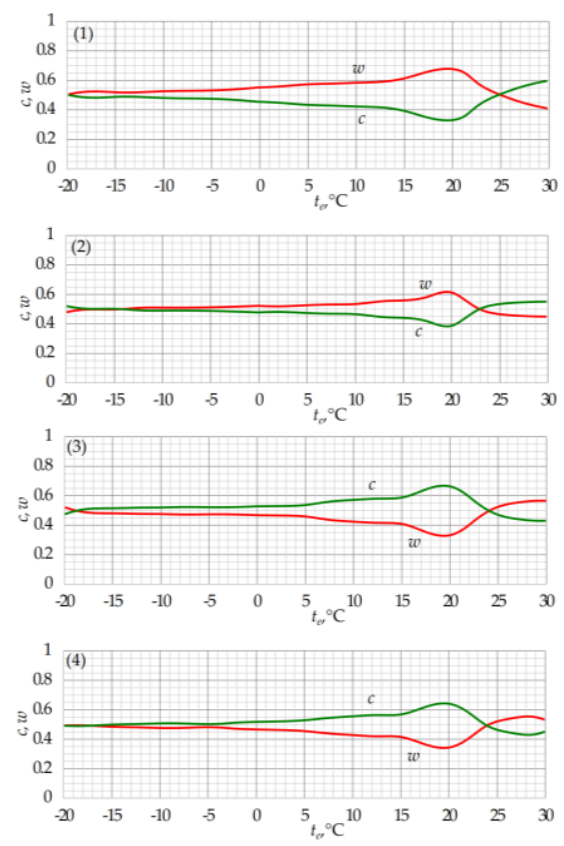

Fig. 7. Portions of warm and cold supply air supplied to individual rooms (1-4) for warm and cold air temperatures ensuring constant and equal inflow to main distribution routes (see Fig. 6.).

\section{Conclusions}

Based on our simulations of the annual operation of the dual-duct ventilation systems, we conclude that the required design parameters of the air supplied to the rooms, and therefore the air within these rooms, can be ensured at different temperature set-points of warm and 
cold airflows. These temperatures, however, must meet the requirements for maximum cold air temperature and minimum warm air temperature throughout the year. The assumed temperatures of warm and cold airflows, in a yearly cycle, regulate warm/cold air portions both at the inlet to the main air distribution system and at the inflow to individual rooms. The main air distribution systems for warm and cold air are designed for the maximum required airflows. Thus, the greater are the fluctuations in the portions of warm and cold air in the yearly operation cycle, the larger are the cross-sections of the designed ventilation ducts. We show that, it is possible to have constant and equal portions of warm and cold air at the inlet to the main distribution ducts in the yearly operation cycle of the dual-duct system, regardless of the variable external and internal conditions. In order to achieve this balance, warm and cold air temperatures should be set in the function of thermal processes occurring within rooms, external air parameters and instantaneous warm and cold airflows. In addition, it should be possible to lower the temperature of the warm air (below the temperatures of the external air and in the rooms) during the transitional and summer periods. With constant portions of warm and cold airflows distributed within main system, individual mixing boxes may be supplied with significantly distinct and varying portions of warm and cold airflows as a response to individual room heat gains.

\section{References}

1. A. D’Orazio, C. Agostini, Science \& Techn. for the Built Env. 22, 3, 281-289 (2016)

2. D. Dong, M. Liu, J. Wang, Proceedings of $5^{\text {th }}$ International Conf. for Enhanced Building Operations (2005)

3. M. Liu, M. Abbas, Y. Zhu, D. E. Claridge, Proceedings of $13^{\text {th }}$ Symp. on Improving Building Systems in Hot and Humid Climates (2002)

4. M. Liu, D. E. Claridge, Proceedings of the $11^{\text {th }}$ Symp. on Improving Building Systems in Hot and Humid Climates, 146-160 (1998)

5. M. Liu, D. E. Claridge, ASHRAE Trans. 105, 66-70 (1999)

6. A. Przydróżna, E. Przydróżny, Proceedings of RoomVent \& Ventilation, 547-552 (2018)

7. E. Przydróżny, A. Przydróżna, Proceedings of Clima (2019) (to be published)

8. E. Przydróżny, Wysokosprawne systemy wentylacji $i$ klimatyzacji - technologie i projektowanie (Wydawnictwo Politechniki Wroclawskiej, 2007)

9. E. Przydróżny, A. Przydróżna, S. Szczęśniak, Ther. Science and Eng. Progress 5, 69-85 (2018)

10. E. Przydróżny, S. Szczęśniak, Instal (2014)

11. S. Przydróżny, J. Ferencowicz, Klimatyzacja (Wydawnictwo Politechniki Wroclawskiej, 1988)

12. S. Przydróżny, COW, 11 (1983)

13. S. Przydróżny, COW, 12 (1983)

14. Recknagel, Sprenger, Honnmann, Schramek, Poradnik Ogrzewanie i Klimatyzacja (EWFE Gdansk, 1994)

15. D. Stanke, ASHRAE J. 47, 5, 20-30 (2005)

16. S. T. Taylor, D. Heinzerling, ASHRAE J. 60, 8, 35-43 (2018)

17. G. Wei, J. Martinez, T. Miniham, Proceedings of the $3^{\text {rd }}$ Internat. Conf. for Enhanced Building Operations (2003) 